\title{
The Emerging Link between the Hippo Pathway and Non-coding RNA
}

\author{
Mayuko Shimoda ${ }^{a}$ and Toshiro Moroishi*,a,b,c \\ ${ }^{a}$ Department of Cell Signaling and Metabolic Medicine, Faculty of Life Sciences, Kumamoto \\ University; 1-1-1 Honjo, Kumamoto 860-8556, Japan: ${ }^{b}$ Center for Metabolic Regulation of \\ Health Aging, Faculty of Life Sciences, Kumamoto University; 1-1-1 Honjo, Kumamoto 860-8556, \\ Japan: and ${ }^{c}$ Precursory Research for Embryonic Science and Technology (PRESTO), Japan \\ Science and Technology Agency (JST); 4-1-8 Honcho, Kawaguchi, Saitama 332-0012, Japan.
} Received September 16, 2019

\begin{abstract}
The Hippo intracellular signaling pathway plays a pivotal role in cell fate determination. Although previous studies have identified many components of the Hippo pathway, the whole picture of the Hippo network is just beginning to be delineated. Recent discoveries in the past decade have shed light on a newly discovered signaling network where the Hippo pathway interplays with several types of non-coding RNAs, including microRNAs, long non-coding RNAs and circular RNAs, to mediate diverse biological processes. Those non-coding RNAs communicate with each other to maintain cellular homeostasis. In this review article, we summarize the current and emerging understanding of the roles of non-coding RNAs in the regulation of and by the Hippo pathway.
\end{abstract} eration

Key words Hippo pathway; non-coding RNA; competing endogenous RNA; signal crosstalk; cancer; regen-

\section{INTRODUCTION}

The Hippo pathway is an evolutionarily conserved signaling cascade that controls organ development, ${ }^{1-4)}$ stem cell biology, ${ }^{5-7)}$ regeneration, ${ }^{8-10)}$ and cancer. ${ }^{11-13)}$ The Hippo pathway was first identified as a key signal that contributes to the control of organ size in Drosophila melanogaster. Later observation that this pathway is conserved in mammals has attracted great interest in recent years, as experimental evidence has shown that the Hippo pathway is a main regulator of cell-fate determination, including cell proliferation, cell survival, and differentiation. Previous studies have revealed that the physiological properties of tissue architecture affect the activity of the Hippo pathway (Fig. 1). For instance, the Hippo pathway is regulated by cell-cell contact ${ }^{14,15)}$ and cell polarity, ${ }^{16-18)}$ as well as by mechanical cues ${ }^{19-23)}$ such as extracellular matrix stiffness and traction forces exerted by neighboring cells. In addition to those physical cues, a general role of extracellular signaling pathways has become apparent, such as G-proteincoupled receptors ${ }^{24-27)}$ and the Wnt signaling pathway, ${ }^{28-31)}$ in the regulation of the Hippo pathway. Moreover, cellular stress signals, ${ }^{32-35)}$ as well as metabolism and nutrient signals, ${ }^{36-41)}$ also contribute to the regulation of the Hippo pathway. Disruption of the Hippo pathway causes tissue overgrowth and confers principal features of cancer ${ }^{42-44)}$ including increased cell proliferation and survival, ${ }^{45}$ ) abnormal cell division, ${ }^{46,47)}$ and enhanced cell migration. ${ }^{48,49)}$ In contrast, aberrant activation of the Hippo pathway impairs tissue development, stem cell maintenance, and differentiation. ${ }^{50)}$ In addition to those cell-autonomous functions, recent studies revealed that the Hippo pathway also mediates non-cell autonomous functions, such as cell competition ${ }^{51-55)}$ and immune responses, ${ }^{56-60)}$ which play a pivotal role in the homeostatic control of multicellular organisms. ${ }^{61,62)}$ Thus, collectively, the Hippo intracellular signaling pathway acts as a nexus and integrator for multiple signals from the cellular microenvironment, regulat- ing multiple aspects of cell biology, and thereby contributing to cell-fate determination ${ }^{63)}$ (Fig. 1).

It is therefore not surprising that a number of novel molecules and drugs are currently under development to modulate the Hippo pathway for cancer treatment and regenerative medicine. ${ }^{8,64)}$ However, despite recent efforts to clarify physiological regulations of and by the Hippo pathway, the molecular mechanisms connecting those physiological cues with the Hippo pathway have not been elucidated. Previous studies established the pivotal role of protein phosphorylation in the regulation of the Hippo pathway. As the Hippo pathway responds to multiple stimuli and exerts diverse functions, it is unlikely that all of those processes are explained by biological processes mediated by proteins, such as protein-protein interaction and protein modification. Indeed, recent studies highlight important functions of metabolites in the regulation of and by the Hippo pathway. ${ }^{65)}$ In this review, we aim to provide a general picture of the emerging roles of non-coding RNAs (ncRNAs) in the Hippo pathway based on current findings. Various types of ncRNA have been revealed to participate in many crucial biological processes. ${ }^{66,67)}$ This emerging link between the Hippo pathway and ncRNA biology will provide a new point of view for our understanding of the biological processes mediated by the Hippo pathway, and will also likely have important clinical implications.

\section{MOLECULAR FUNCTIONS OF THE HIPPO PATHWAY}

Since its initial discovery in fruit flies, our understanding of the Hippo signaling network has been expanding. The Hippo pathway is now known to be composed of more than 30 components. ${ }^{68)}$ The heart of the Hippo pathway includes the kinase module and the transcriptional module (Fig. 2). The kinase module comprises eleven kinases, namely, mammalian STE20-like protein kinase 1 (MST1, also known as STK4) 


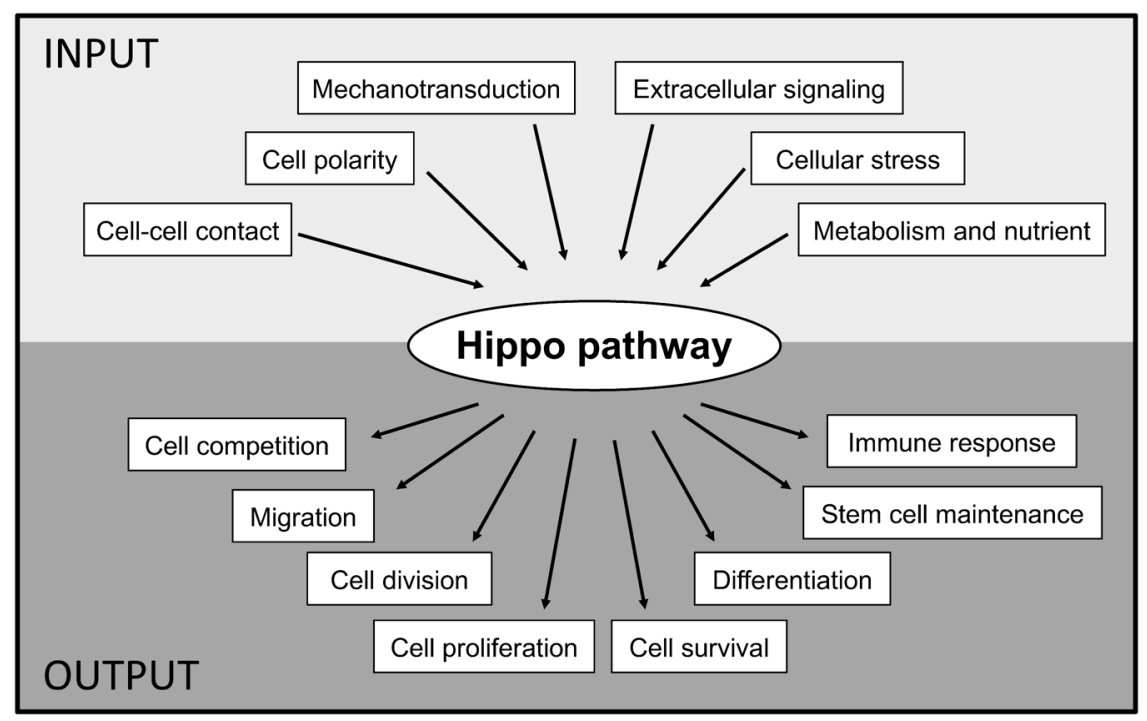

Fig. 1. Regulation of and by the Hippo Pathway in Diverse Cellular Processes

The Hippo intracellular signaling pathway responds to multiple physiological cues from the cellular microenvironment, including cell-cell contact, cell polarity, mechanotransduction, extracellular signaling, and cellular stress, as well as metabolism and nutrient signals. Those signals are integrated by the Hippo pathway, and impact numerous biological processes, such as cell competition, cell migration, cell division and proliferation, cell survival, differentiation, stem cell maintenance, and immune responses. Therefore, the Hippo pathway acts as a nexus and integrator for multiple signals in the mediation of cell-fate determination.

and MST2 (also known as STK3), mitogen-activated protein kinase kinase kinase kinase 1/2/3/4/5/6/7 (MAP4K1-7), large tumor suppressor kinase 1 (LATS1) and LATS2, and in addition, their activating six adaptor proteins: salvador family WW domain-containing protein 1 (SAV1), Ras-related proteins RAP2 (including three GTPases, RAP2A/B/C), and MOB kinase activator $1 \mathrm{~A}(\mathrm{MOB} 1 \mathrm{~A})$ and $\mathrm{MOB} 1 \mathrm{~B}$. The transcriptional module includes the two paralogues of transcriptional coactivators, yes-associated protein (YAP) and transcriptional co-activator with PDZ-binding motif (TAZ, also known as WWTR1), in combination with four transcription factor TEA domain family members $1 / 2 / 3 / 4$ (TEAD1-4). When the kinase module is activated (the Hippo pathway is "ON"), MST1/2 or MAP4K1-7 phosphorylate and activate downstream LATS1/2 kinases, which in turn phosphorylate YAP/TAZ. ${ }^{69)}$ Phosphorylated YAP/TAZ are retained in cytoplasm through the interaction with 14-3-3 protein, ${ }^{70)}$ or degraded through the ubiquitin proteasome system. ${ }^{71)}$ In contrast, when the kinase module is inactivated (the Hippo pathway is "OFF"), hypo-phosphorylated YAP/TAZ translocate to the nucleus of a cell and bind to TEAD1-4 to promote target gene transcription. ${ }^{72)}$ YAP and TAZ, in complex with TEAD1-4, generally drive multiple aspects of cell-fate determination, including cell proliferation, cell survival, and differentiation, which is critical for tissue homeostasis. Thus, in short, the activation of LATS1/2 kinases and the inactivation of YAP/TAZ transcriptional co-activators represent the major molecular functions of the Hippo pathway.

\section{INTERPLAY BETWEEN THE HIPPO PATHWAY AND NON-CODING RNA}

Non-coding RNAs comprise the vast majority of primary transcripts derived from genome encoding genes, similar to protein-coding RNAs. These ncRNAs are roughly classified into two major categories according to their length, namely, small ncRNAs (shorter than 200 nucleotides, including micro RNAs (miRNAs) and others) and long non-coding RNAs (lncRNAs, longer than 200 nucleotides). ${ }^{73,74)}$ In addition, circular RNAs (circRNAs) have been identified as a novel class of non-coding RNA that has a covalently closed circular structure lacking both a $5^{\prime}$ cap and a $3^{\prime}$ tail. Convincing studies in recent years have revealed a regulatory network where ncRNAs interplay with the core components of the Hippo pathway to mediate physiological functions of the Hippo pathway. Among the multiple ncRNA subclasses, we summarize the emerging roles of miRNAs, lncRNAs and circRNAs in regulation of and by the Hippo pathway.

3.1. Reciprocal Regulation between miRNA and the Hippo Pathway MiRNAs are small RNAs of approximately 21-25 nucleotides in length; they do not encode functional

\section{Biography}

Dr. Mayuko Shimoda graduated with a B.Sc. from School of Life Sciences, Tokyo University of Pharmacy and Life Sciences supervised by Dr. Masato Tanaka in 2012. She completed M.MSc. and Ph.D. under the supervision of Drs. Nobuo Sakaguchi and Kazuhiko Maeda in Graduate School of Medical Sciences, Kumamoto University in 2018. She worked as a postdoctoral fellow in Dr. Shizuo Akira's lab in Immunology Frontier Research Center (iFReC), Osaka University until 2019, and then joined Dr. Toshiro Moroishi's lab at Kumamoto University. She has been working on the role of RNA biogenesis and metabolism in immune responses. Currently, her research is focusing on the reciprocal interplay between the Hippo intracellular signaling pathway and non-coding RNA biology.

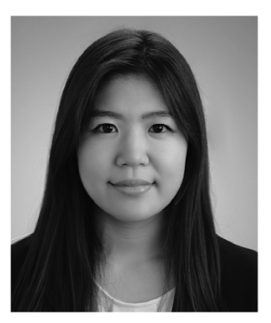

Mayuko Shimoda 


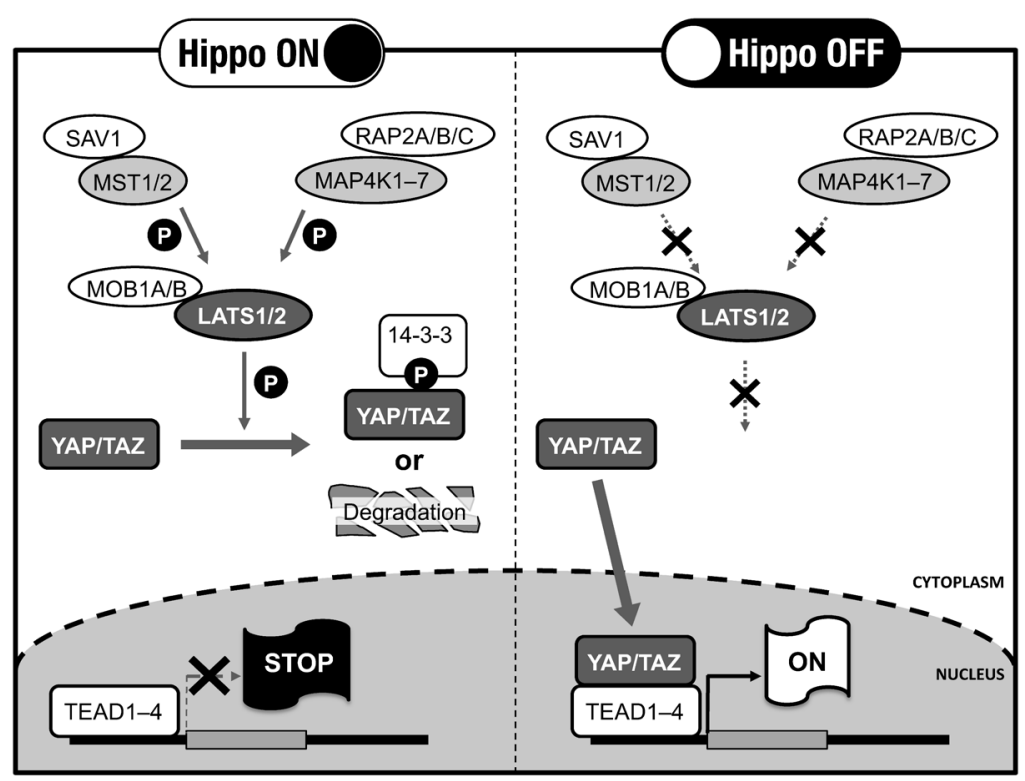

Fig. 2. Molecular Functions of the Hippo Pathway

The left and right panels represent the "ON" and "OFF" status of the Hippo pathway, respectively. The Hippo pathway is composed of both a kinase module and a transcriptional module. The kinase module comprises eleven kinases: mammalian STE20-like protein kinase 1 (MST1) and MST2, mitogen-activated protein kinase kinase kinase kinase 1/2/3/4/5/6/7 (MAP4K1-7), large tumor suppressor kinase 1 (LATS1) and LATS2. In addition, the kinase module requires six adaptor proteins: salvador family WW domain-containing protein 1 (SAV1), Ras-related proteins RAP2 (including three GTPases RAP2A/B/C), and MOB kinase activator 1A (MOB1A) and MOB1B. The transcriptional module includes the transcriptional co-activators, yes-associated protein (YAP) and transcriptional co-activator with PDZ-binding motif (TAZ), associated with the transcription factors TEA domain family members 1/2/3/4 (TEAD1-4). In the left panel, when the Hippo pathway is "ON," the kinase module inhibits the transcriptional module by mediating inhibitory phosphorylation on YAP/TAZ. Phosphorylated YAP/TAZ are retained in cytoplasm by interacting with 14-3-3 proteins, or are degraded through the ubiquitin-proteasome pathway. In contrast, when the Hippo pathway is "OFF" (right panel), hypo-phosphorylated YAP/TAZ translocate into the nucleus, where they bind to TEAD transcription factors to promote target gene transcription.

proteins. MiRNA was first discovered in Caenorhabditis elegans as small RNA transcripts that suppress LIN-14 protein expression. $^{75,76)}$ MiRNAs negatively regulate protein expression at the post-transcriptional level by interacting with a complementary sequence typically located in the $3^{\prime}$ untranslated region (UTR) of the target transcript. ${ }^{77)}$ Previous studies have revealed an important function of the Hippo pathway in the regulation of miRNA biogenesis (Fig. 3). YAP/TAZ in the nucleus have been found to bind to DEAD box helicase 17 (DDX17) (also known as p72) to suppress its association with the Microprocessor complex that regulates miRNA processing. ${ }^{78)}$ Cell density-dependent activation of the Hippo pathway, thus, generally promotes global miRNA biogenesis. ${ }^{78)}$ In cytoplasm, the hairpin structure of miRNA precursor is cleaved by the ribonuclease DICER to generate a mature miRNA duplex. $^{79)}$ Intriguingly, nuclear YAP/TAZ conversely stimulate the biogenesis of several miRNAs, such as miR-16, -21, $-23 \mathrm{a}$, and -107 , by increasing DICER expression via the Let-7 family of miRNAs. ${ }^{80)}$ In addition, YAP directly induces the transcription of certain miRNAs, such as miR-29. ${ }^{81)}$ Another study demonstrated that NF2, an upstream activator of the Hippo pathway, promotes the biogenesis of the Let-7 family of miRNAs by sequestering its inhibitor, LIN28B. ${ }^{82}$ Therefore, the Hippo pathway may function as both a positive and negative regulator of miRNA biogenesis in a context- and targetdependent manner. Further investigations clarifying how the Hippo pathway takes advantage of this bidirectional regulation of miRNA biogenesis in both physiological and pathological contexts will broaden our understanding of miRNA biology regulated by the Hippo pathway.

Following cleavage by DICER, a single strand miRNA is loaded onto Argonaute 2 (AGO2) protein as part of the

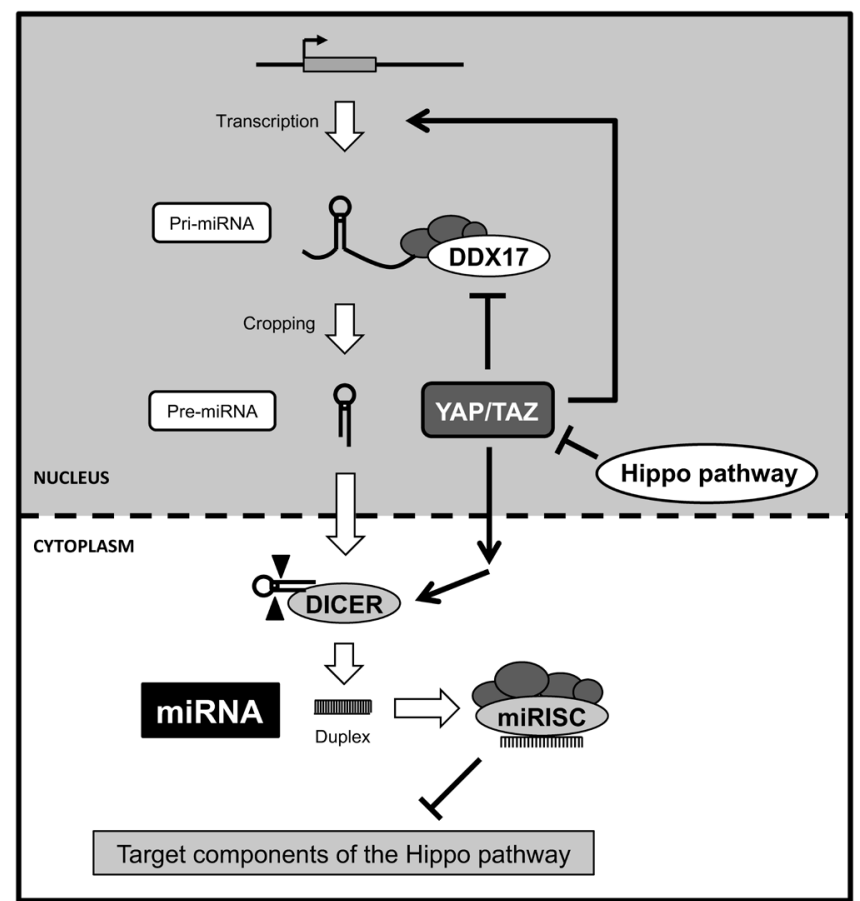

Fig. 3. Biogenesis of miRNAs and Their Interplay with the Hippo Pathway

In the nucleus, primary micro RNA (miRNA) transcript (pri-miRNA) is cleaved by the Microprocessor complex that contains DEAD box helicase 17 (DDX17) to generate pre-miRNA. The hairpin structure of the miRNA precursor is cleaved by the ribonuclease DICER in the cytoplasm, then loaded onto the miRNA-induced silencing complex (miRISC) to promote gene silencing of the target mRNA in the Hippo pathway. Nuclear YAP/TAZ bind to DDX17 and abrogate its association with the Microprocessor complex to inhibit global miRNA biogenesis. In contrast, YAP/TAZ also stimulate the biogenesis of several miRNAs by increasing the expression of DICER. Therefore, the Hippo pathway functions as both a positive and negative regulator of miRNA biogenesis in a context-dependent manner. 
Table 1. Regulation of the Hippo Pathway by miRNAs

\begin{tabular}{|c|c|c|c|c|c|}
\hline miRNA & Target & Effect on the Hippo pathway & Biological function & Context & Reference \\
\hline miR-9 and miR-137 & CUL4A & $\begin{array}{l}\text { Increases the expression of LATS1 by } \\
\text { suppressing the expression of CUL4A that } \\
\text { targets LATS } 1 \text { for proteasomal degradation }\end{array}$ & $\begin{array}{l}\text { Suppresses cancer cell proliferation } \\
\text { and invasion }\end{array}$ & Gastric cancer & Deng et al., 2016 $6^{109)}$ \\
\hline miR-29-3p & DNMT3B & $\begin{array}{l}\text { Increases the expression of LATS1 by sup- } \\
\text { pressing the expression of DNMT3B that } \\
\text { promotes promoter methylation of LATS1 } \\
\text { locus and consequent gene repression }\end{array}$ & $\begin{array}{l}\text { Suppresses cancer cell proliferation } \\
\text { and migration, as well as tumor } \\
\text { growth in nude mice }\end{array}$ & $\begin{array}{l}\text { Hepatocellular } \\
\text { carcinoma }\end{array}$ & Wu et al., 2019 \\
\hline miR-199a-3p & $\begin{array}{l}\text { TAOK1, } \\
\beta \text {-TrCP, and } \\
\text { NDR2 }\end{array}$ & $\begin{array}{l}\text { Increases protein expression and nuclear } \\
\text { localization of YAP by suppressing multiple } \\
\text { Hippo pathway components }\end{array}$ & Induces cardiomyocyte proliferation & Cardiomyocyte & $\begin{array}{l}\text { Torrini et al., } \\
2019^{111)}\end{array}$ \\
\hline miR-200a & YAP & $\begin{array}{l}\text { Decreases the expression of YAP by target- } \\
\text { ing 3' UTR of those mRNA }\end{array}$ & $\begin{array}{l}\text { Attenuates anoikis-induced apoptosis } \\
\text { in cancer cells }\end{array}$ & Breast cancer & Yu et al., 2013 ${ }^{85)}$ \\
\hline $\begin{array}{l}\text { miR-200 family (miR- } \\
\text { 200a, -200b, -200c, } \\
\text {-141, and -429) }\end{array}$ & $\begin{array}{l}\text { LATS } 1 / 2 \text {, and } \\
\text { PTPN14 }\end{array}$ & $\begin{array}{l}\text { Promotes nuclear localization of YAP by } \\
\text { suppressing multiple Hippo pathway compo- } \\
\text { nents, but simultaneously represses YAP } \\
\text { target genes, such as } C T G F\end{array}$ & $\begin{array}{l}\text { Represses cell proliferation, migra- } \\
\text { tion, and formation of adherens } \\
\text { junctions }\end{array}$ & Hair morphogenesis & $\begin{array}{l}\text { Hoefert et al., } \\
2018^{87)}\end{array}$ \\
\hline $\begin{array}{l}\mathrm{miR}-302 / 367 \text { cluster } \\
\quad(\mathrm{miR}-302 \mathrm{a},-302 \mathrm{~b} \\
-302 \mathrm{c},-302 \mathrm{~d} \text {, and } \\
-367)\end{array}$ & $\begin{array}{l}\text { MOB1B, } \\
\text { LATS2, and } \\
\text { MST1 }\end{array}$ & $\begin{array}{l}\text { Promotes nuclear localization of YAP } \\
\text { by suppressing multiple Hippo pathway } \\
\text { components }\end{array}$ & $\begin{array}{l}\text { Increases cardiomyocyte proliferation } \\
\text { in embryonic and postnatal hearts, } \\
\text { promotes adult cardiac regeneration } \\
\text { after myocardial infarction }\end{array}$ & $\begin{array}{l}\text { Heart development } \\
\text { and regeneration }\end{array}$ & Tian et al., 2015 \\
\hline $\begin{array}{l}\mathrm{miR}-302 / 367 \text { cluster } \\
\text { (miR-302a, }-302 \mathrm{~b} \\
-302 \mathrm{c},-302 \mathrm{~d} \text {, and } \\
-367)\end{array}$ & LATS2 & $\begin{array}{l}\text { Decreases the expression of LATS } 2 \text { by } \\
\text { targeting } 3 \text { ' UTR of its mRNA }\end{array}$ & $\begin{array}{l}\text { Promotes cancer cell proliferation, } \\
\text { sphere formation, invasion, and } \\
\text { tumor growth in nude mice }\end{array}$ & Prostate cancer & Guo et al., 2017 $7^{113)}$ \\
\hline $\operatorname{miR}-375$ & $\begin{array}{l}\text { YAP1, } \\
\text { TEAD4 and } \\
\text { CTGF }\end{array}$ & $\begin{array}{l}\text { Decreases the expression of YAP, TEAD4, } \\
\text { and CTGF by targeting } 3^{\prime} \text { UTR of those } \\
\text { mRNA }\end{array}$ & $\begin{array}{l}\text { Inhibits cancer cell proliferation and } \\
\text { invasion, as well as tumor growth in } \\
\text { nude mice }\end{array}$ & Gastric cancer & Kang et al., 2018 $8^{114)}$ \\
\hline $\operatorname{miR}-506-3 p$ & YAP & $\begin{array}{l}\text { Suppresses the expression of YAP by } \\
\text { targeting } 3^{\prime} \text { UTR of its mRNA }\end{array}$ & Not validated & $\begin{array}{l}\text { Esophageal squamous } \\
\text { cell carcinoma }\end{array}$ & Wang et al., 2019 115$)$ \\
\hline $\operatorname{miR}-4269$ & TEAD1/4 & $\begin{array}{l}\text { Decreases the expression of TEAD } 1 / 4 \text { by } \\
\text { targeting } 3^{\prime} \text { UTR of those mRNA }\end{array}$ & $\begin{array}{l}\text { Suppresses cancer cell prolifera- } \\
\text { tion and invasion, as well as tumor } \\
\text { growth in nude mice }\end{array}$ & Gastric cancer & Zhou et al., 2017 $7^{116)}$ \\
\hline
\end{tabular}

miRNA-induced silencing complex (miRISC) to promote gene silencing of the target mRNA (Fig. 3). Those mature miRNAs in turn modulate the activity of the Hippo pathway. A large number of miRNAs have been linked to the Hippo pathway to date, the majority of which were characterized in the context of cancer biology. ${ }^{83)}$ The molecular actions and biological effects of several miRNAs are highlighted in Table 1. Each miRNA displays distinct mRNA targeting in the Hippo pathway, and even the effect of the same miRNA on the Hippo pathway is cell-type- and context-dependent. For example, miR-200 family miRNAs (include five members; miR-200a, -200b, -200c, -141, and -429) are one of the wellknown inhibitors of the epithelial mesenchymal transition that confers malignant properties to cancer cells. ${ }^{84)}$ MiR-200a has been shown to directly suppress YAP in human breast cancer cells, ${ }^{85)}$ as well as TAZ in colon cancer cells, ${ }^{86)}$ yet the overexpression of the miR-200 family in the developing skin of mice has been reported to promote YAP nuclear localization by targeting multiple upstream components of the Hippo pathway ${ }^{87)}$ One possibility for the diverse functions of miRNAs in the regulation of the Hippo pathway is that miRNAs can target multiple components in the same pathway ${ }^{88)}$; conversely, a single component in the Hippo pathway could be regulated by multiple miRNAs. This complexity adds an extra layer of divergent regulation of the Hippo pathway by miRNAs in different tissues and biological processes; an integrated view of the miRNA network that orchestrates the complex physiological and pathological functions of the Hippo pathway remains to be elucidated.

Recent advances in RNA-sequencing technology have re- vealed the existence of approximately 7500 small ncRNAs (including 1800 miRNAs) as well as 18000 lncRNAs, in addition to 20000 protein-coding genes in the human genome. ${ }^{89}$ As described above, the regulatory ncRNAs, such as miRNAs, play important roles in gene expression mainly by controlling the expression levels of the protein-coding RNAs. However, the physiological function of the vast majority of ncRNAs remains to be clarified. Although there has been scientific debate, one interesting hypothesis to explain the existence of a large number of ncRNAs in the human genome is the competing endogenous RNA (ceRNA) hypothesis. ${ }^{90)}$ MiRNAs recognize their target mRNAs by using as few as 6-8 nucleotides at the $5^{\prime}$ end of the miRNA, namely the seed region. ${ }^{88)}$ Recent studies have revealed that certain ncRNAs, including lncRNAs and, to a lesser extent, circRNAs, compete with mRNA for interaction with the seed region of miRNAs, ${ }^{90,91)}$ and therefore, those ncRNAs can act as molecular sponges or decoys to suppress the targeting of mRNAs by miRNAs (Fig. 4). Indeed, experimentally designed decoy RNAs have been shown to act as molecular sponges to inhibit the function of miRNAs. ${ }^{92)}$ In addition to the known functions of ncRNAs in transcriptional regulation, or in mediating protein-protein interaction, ${ }^{91,93)}$ ncRNAs act as ceRNAs to regulate other RNA transcripts by competing for shared miRNAs.

We next discuss the emerging roles of lncRNAs and circRNAs in the regulation of the Hippo pathway.

3.2. Regulation of the Hippo Pathway by IncRNA LncRNAs are defined as RNA transcripts with lengths exceeding 200 nucleotides and not translated into proteins. LncRNAs are transcribed in both sense and antisense directions by 


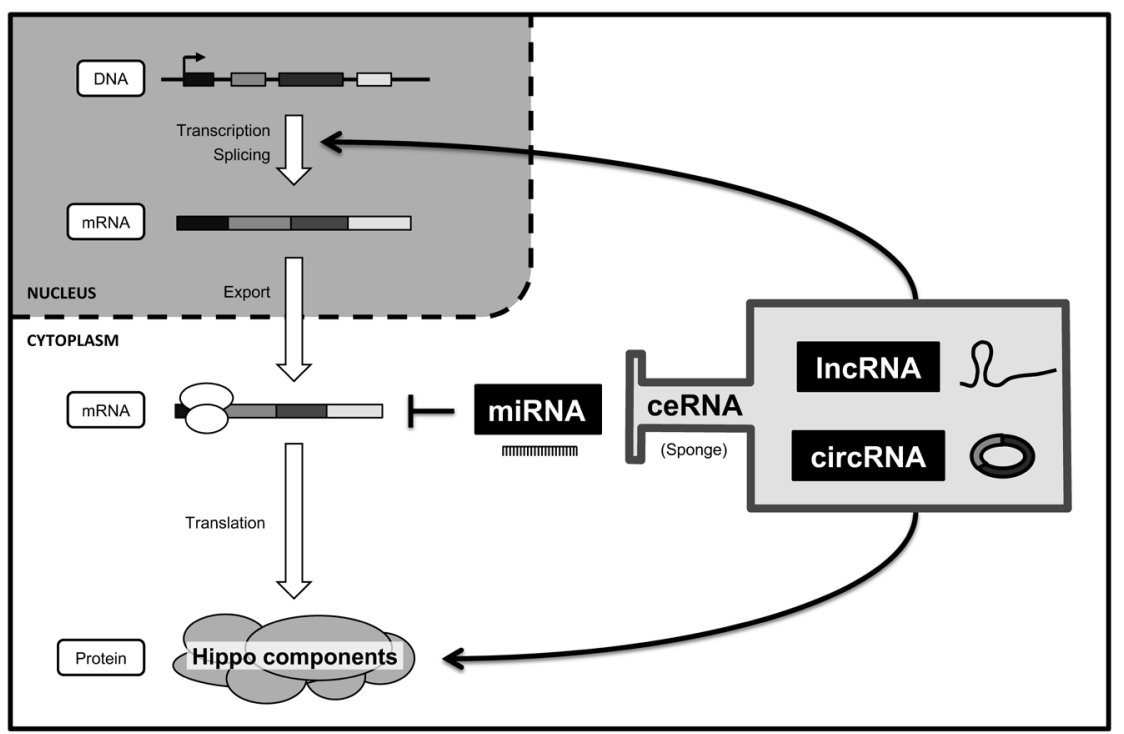

Fig. 4. Diverse Molecular Functions of ncRNAs

MiRNAs function by mainly suppressing the expression levels of protein-coding mRNAs. Other types of non-coding RNAs (ncRNAs), including long non-coding RNAs (lncRNAs) and circular RNAs (circRNAs), can regulate transcription, RNA splicing, and protein-protein interaction via direct binging. In the competing endogenous RNA (ceRNA) hypothesis, it is proposed that lncRNAs and circRNAs compete with mRNA for interaction with miRNAs, and therefore serve as molecular sponges to suppress the targeting of mRNAs by miRNAs. Thus, the ceRNA network involving lncRNA/circRNA-miRNA-mRNA regulates the activity of the Hippo pathway by multiple mechanisms.

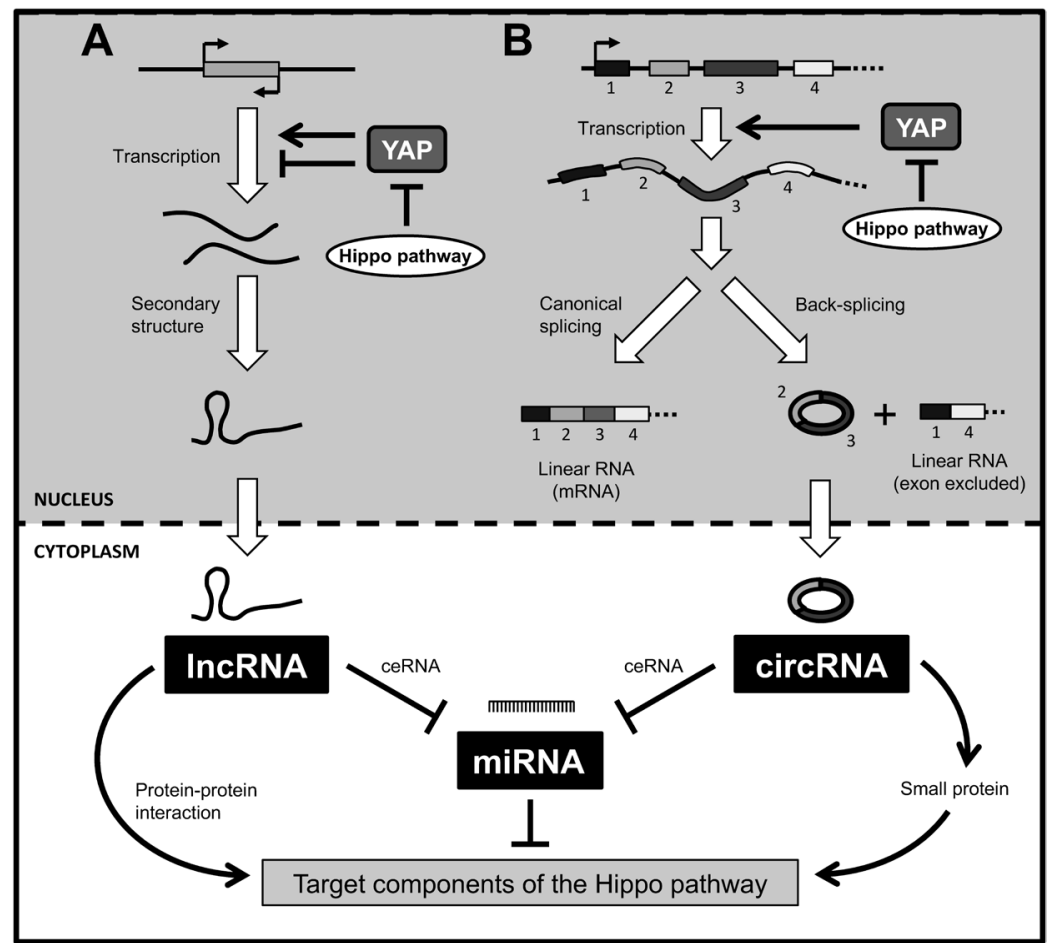

Fig. 5. Biogenesis and Molecular Functions of lncRNAs and circRNAs in the Regulation of the Hippo Pathway

(A) LncRNAs are transcribed in both sense and antisense directions, and mature lncRNA transcripts represent unique secondary structures that can interact with DNA, RNA, or proteins. LncRNAs thus modulate protein-protein interaction via direct binding in the regulation of the Hippo pathway. LncRNAs also function as ceRNAs to regulate the expression of Hippo pathway components, and conversely, YAP can affect the transcription of certain lncRNAs. (B) CircRNAs are single-stranded transcripts that have a covalent closed-loop structure resulting from a $3^{\prime}$ to $5^{\prime}$ end-joining event, namely back-splicing. CircRNAs function as ceRNAs, or they encode a small protein to modulate the activity of the Hippo pathway. YAP is reported to regulate the transcription of specific circRNAs.

RNA Polymerase II, then polyadenylated and spliced in the same fashion as mRNA ${ }^{93}$ (Fig. 5A). Mature lncRNA transcripts represent unique secondary structures that can interact with DNA, RNA, or proteins, and thereby modulate gene transcription, post-transcriptional gene expression, and also protein-protein interaction. ${ }^{93)}$ Recent studies have revealed broad roles of lncRNAs in mediating numerous biological processes during disease development and progression, ${ }^{67,94}$ and IncRNAs are also emerging as an important mediator of the Hippo pathway. For instance, YAP in a complex with TEAD4 promotes the transcription of BCAR4 lncRNA, which subsequently modulates Hedgehog signaling to enhance the 
Table 2. Effects of lncRNAs on the Hippo Pathway

\begin{tabular}{|c|c|c|c|c|}
\hline $\operatorname{lncRNA}$ & Effect on the Hippo pathway & Biological function & Context & Reference \\
\hline MALAT1 & $\begin{array}{l}\text { Prevents TEADs-YAP binding via direct binding, and inhibits } \\
\text { their target gene expression }\end{array}$ & Suppresses cancer metastasis & Breast cancer & Kim et al., 2018 ${ }^{98)}$ \\
\hline MAYA & $\begin{array}{l}\text { Induces inhibitory methylation of MST1 by serving as a scaffold } \\
\text { for a methyltransferase complex }\end{array}$ & Promotes bone metastasis of cancer cells & Breast cancer & Li et al., 2017 $7^{100)}$ \\
\hline Nkx2-2as & $\begin{array}{l}\text { Increases the expression of LATS } 1 / 2 \text { by functioning as a sponge } \\
\text { for miR-103a, miR-107, and miR- } 548 \mathrm{~m}\end{array}$ & $\begin{array}{l}\text { Suppresses cancer cell proliferation and inva- } \\
\text { sion, as well as tumor growth in nude mice }\end{array}$ & Medulloblastoma & Zhang et al., 2018 ${ }^{117)}$ \\
\hline SNHG1 & $\begin{array}{l}\text { Increases the expression of YAP by functioning as a sponge for } \\
\text { miR-375 }\end{array}$ & Promotes cancer cell proliferation and migration & $\begin{array}{l}\text { Laryngeal squamous } \\
\text { cell carcinoma }\end{array}$ & Gao et al., 2018 ${ }^{118)}$ \\
\hline SNHG15 & $\begin{array}{l}\text { Increases the expression of YAP by functioning as a sponge for } \\
\text { miR-200a-3p }\end{array}$ & $\begin{array}{l}\text { Promotes cell proliferation and inhibits apopto- } \\
\text { sis, supporting tumor growth in nude mice }\end{array}$ & $\begin{array}{l}\text { Papillary thyroid } \\
\text { cancer }\end{array}$ & Wu et al., 2018 ${ }^{101)}$ \\
\hline ZFAS1 & $\begin{array}{l}\text { Increases the expression of YAP and TEAD } 1 \text { by functioning as } \\
\text { a sponge for miR-27a, miR-15a, and miR-16 }\end{array}$ & $\begin{array}{l}\text { Promotes cancer cell proliferation and invasion, } \\
\text { as well as tumor growth in nude mice }\end{array}$ & Prostate cancer & Cui et al., 2019 119$)$ \\
\hline
\end{tabular}

transcription of the key glycolytic enzymes. ${ }^{95)}$ YAP activation thus promotes glycolysis in cancer cells via lncRNAs. As glucose metabolism is one of the potent regulators of the Hippo pathway, ${ }^{65)}$ this study not only highlighted the signal crosstalk mediated by lncRNAs, but also revealed an intimate relationship between the Hippo pathway and glucose homeostasis. Notably, therapeutic delivery of locked nucleic acids targeting BCAR4 attenuated YAP-dependent glycolysis and breast cancer growth, suggesting a therapeutic potential for targeting the Hippo--IncRNA axis in cancer treatment. ${ }^{95)}$ Similarly, YAP in complex with TCF4/ $\beta$-catenin has been shown to promote the expression of MALAT1 lncRNA in liver cancer ${ }^{96)}$ and colon cancer $^{97)}$ to enhance the tumorigenic properties of cancer cells, such as cell proliferation and migration. Of note, the tumor promoting effects of MALAT1 could be cell-type- and context-dependent, as it has been shown that MALAT1 suppresses breast cancer metastasis by inactivating TEAD-mediated transcription via direct binding. ${ }^{98)}$ In addition, YAP has also been shown to function in suppressing certain lncRNA expression, such as MT1DP, ${ }^{99)}$ though the precise underlying molecular mechanism awaits further elucidation. These studies highlight an important function of lncRNAs in mediating various functions downstream of the Hippo pathway.

LncRNAs also regulate the Hippo pathway through multiple mechanisms. As summarized in Table 2, many lncRNAs have been reported to affect the activity of the Hippo pathway, especially in the context of cancer cell growth and metastasis. Some lncRNA transcripts directly bind to the components of the Hippo pathway and modulate their protein-protein interaction. For example, the lncRNA MAYA provides a scaffold for the methyltransferase NSUN6 to promote MST1 methylation that leads to the inactivation of MST1 and consequent YAP/TAZ target gene activation in breast cancer cells. ${ }^{100)}$ Another mechanism of action for lncRNA-mediated Hippo pathway regulation is that lncRNAs act as ceRNAs to suppress the targeting of mRNAs by miRNAs. This includes miR-200a-3p targeting by SNHG15 1 ncRNA. ${ }^{101)}$ As described above, miR-200a targets YAP mRNA in human breast cancer cells. ${ }^{85)}$ Similar effects have been observed in papillary thyroid carcinoma cells, where SNHG15 serves as a ceRNA to increase YAP expression by sponging miR-200a-3p. ${ }^{101)}$ Therefore, the ceRNA network involving lncRNA-miRNA-mRNA regulates the complex activity of the Hippo pathway during cancer progression.

3.3. Regulation of the Hippo Pathway by circRNA CircRNAs are single-stranded transcripts that have a co- valent closed-loop structure resulting from a $3^{\prime}$ to $5^{\prime}$ endjoining event, which protects them from degradation by ribonuclease and thus makes them more stable compared to linear RNAs. ${ }^{91,102)}$ CircRNAs are presumably generated by a low-efficient splicing process, namely, back-splicing circularization, and their biogenesis is closely associated with the production of a linear RNA counterpart during splicing. Apart from canonical splicing that joins the upstream $5^{\prime}$ end of the intron (donor site) with the downstream $3^{\prime}$ end of the intron (acceptor site), back-splicing ligates a downstream $5^{\prime}$ donor site reversely with an upstream $3^{\prime}$ acceptor site, resulting in a covalently closed transcript (circRNA), together with an alternatively spliced linear RNA with skipped exons. ${ }^{91,102)}$ (Fig. 5B) Although the functions of most circRNAs are still uncharacterized, recent studies have linked some circRNAs to the Hippo pathway, where circRNAs serve as ceRNAs to mediate miRNA functions. The transcription complex involving YAP, TEAD1, and mutant p53 has been shown to enhance the expression of the tumor-promoting circRNA circPVT1, which suppresses miR-497-5p expression to promote cell proliferation. ${ }^{103)}$ Intriguingly, circPVT1 forms a feed-forward loop to enhance its own expression by directly binding to YAP, suggesting an important function of circRNA downstream of the Hippo pathway in the progression of squamous cell carcinoma. ${ }^{103)}$ CircRNAs also regulate the activity of the Hippo pathway, as evidenced by a study demonstrating that circ_104075 promotes YAP expression by sequestering its suppressor miRNA miR-582-3p in hepatocellular carcinoma. ${ }^{104)}$ Similarly, circLARP4 inhibits cell proliferation and invasion in gastric cancer by functioning as a sponge for miR-424-5p that suppresses LATS1 expression. ${ }^{105)}$ Notably, another study has demonstrated an interesting mechanism: the circRNA circPPP1R12A actually encodes a small protein to enhance YAP-dependent tumorigenesis by inhibiting the Hippo pathway through a currently uncharacterized mechanism involving downregulation of MST1 and LATS1. ${ }^{106)}$ Although our understanding of the interplay between the Hippo pathway and circRNA biology is just emerging, these findings highlight a divergent regulation of the Hippo pathway by a regulatory network involving various types of ncRNAs.

\section{CONCLUDING REMARKS}

Over the past decade, our understanding of the Hippo signaling network has been expanded considerably with the identification of upstream regulatory signals as well as 
downstream biological functions. Despite continuous efforts to develop drugs that target the Hippo pathway for the treatment of human diseases, specific potent inhibitors have not yet been established. Previous strategies for such drug development have been associated with targeting the interaction between YAP/TAZ and TEAD transcription factors ${ }^{13)}$ which are fundamentally difficult to target. It is generally easier to design an oligonucleotide that binds RNA and inhibits its function than to find a small molecule that directly inhibits the protein's function. ${ }^{107)}$ Indeed, certain locked nucleic acids that target ncRNAs have been shown to affect the activity of the Hippo pathway, modulating several biological processes. ${ }^{95,100,108)}$ Thus, the emerging link between the Hippo pathway and ncRNAs not only contributes to our understanding of the composition of the divergent Hippo network, but also, when further dissected, provides a new therapeutic approach to target this pathway in the treatment of human diseases, such as cancer and tissue degeneration. Further investigations to clarify this link will have important implications for future drug discovery.

Acknowledgments The authors thank Dr. Kazuhiko Maeda (Osaka University) and all members of the Moroishi laboratory for critical discussion and constructive comments. Work in the Moroishi laboratory is supported by JST PRESTO [JPMJPR17HA], JSPS KAKENHI [JP18K19433 and JP18H02438], Mitsubishi Foundation, Naito Foundation, Nakajima Foundation, Daiichi Sankyo Foundation of Life Science, Mochida Memorial Foundation for Medical and Pharmaceutical Research, MSD Life Science Foundation Public Interest Incorporated Foundation, Astellas Foundation for Research on Metabolic Disorders, Bristol-Myers Squibb Foundation, Yasuda Medical Foundation, Shinnihon Foundation of Advanced Medical Treatment Research, Uehara Memorial Foundation, Kao Foundation for Arts and Sciences, Taiju Life Social Welfare Foundation, and Japan Foundation for Applied Enzymology.

Conflict of Interest The authors declare no conflict of interest.

\section{REFERENCES}

1) Zheng Y, Pan D. The Hippo signaling pathway in development and disease. Dev. Cell, 50, 264-282 (2019).

2) Irvine KD, Harvey KF. Control of organ growth by patterning and hippo signaling in Drosophila. Cold Spring Harb. Perspect. Biol., 7, a019224 (2015).

3) Sasaki H. Roles and regulations of Hippo signaling during preimplantation mouse development. Dev. Growth Differ., 59, 12-20 (2017).

4) Ishihara E, Nishina $H$. The Hippo-YAP pathway regulates 3D organ formation and homeostasis. Cancers (Basel), 10, 122 (2018).

5) Mo JS, Park HW, Guan KL. The Hippo signaling pathway in stem cell biology and cancer. EMBO Rep., 15, 642-656 (2014).

6) Barry ER, Camargo FD. The Hippo superhighway: signaling crossroads converging on the Hippo/Yap pathway in stem cells and development. Curr. Opin. Cell Biol., 25, 247-253 (2013).

7) Elbediwy A, Vincent-Mistiaen ZI, Thompson BJ. YAP and TAZ in epithelial stem cells: a sensor for cell polarity, mechanical forces and tissue damage. BioEssays, 38, 644-653 (2016).

8) Johnson R, Halder G. The two faces of Hippo: targeting the Hippo pathway for regenerative medicine and cancer treatment. Nat. Rev. Drug Discov., 13, 63-79 (2014)

9) Moya IM, Halder G. Hippo-YAP/TAZ signalling in organ regeneration and regenerative medicine. Nat. Rev. Mol. Cell Biol., 20, 211-226 (2019).

10) Fu V, Plouffe SW, Guan KL. The Hippo pathway in organ development, homeostasis, and regeneration. Curr. Opin. Cell Biol., 49, 99-107 (2017).

11) Moroishi $T$, Hansen CG, Guan KL. The emerging roles of YAP and TAZ in cancer. Nat. Rev. Cancer, 15, 73-79 (2015).

12) Zanconato F, Cordenonsi M, Piccolo S. YAP and TAZ: a signalling hub of the tumour microenvironment. Nat. Rev. Cancer, 19, 454-464 (2019).

13) Calses PC, Crawford JJ, Lill JR, Dey A. Hippo pathway in cancer: aberrant regulation and therapeutic opportunities. Trends Cancer, 5, 297-307 (2019).

14) Zhao B, Wei X, Li W, Udan RS, Yang Q, Kim J, Xie J, Ikenoue T, Yu J, Li L, Zheng P, Ye K, Chinnaiyan A, Halder G, Lai ZC, Guan KL. Inactivation of YAP oncoprotein by the Hippo pathway is involved in cell contact inhibition and tissue growth control. Genes Dev., 21, 2747-2761 (2007).

15) Ota M, Sasaki H. Mammalian Tead proteins regulate cell proliferation and contact inhibition as transcriptional mediators of Hippo signaling. Development, 135, 4059-4069 (2008).

16) Chen CL, Gajewski KM, Hamaratoglu F, Bossuyt W, SansoresGarcia L, Tao C, Halder G. The apical-basal cell polarity determinant Crumbs regulates Hippo signaling in Drosophila. Proc. Natl. Acad. Sci. U.S.A., 107, 15810-15815 (2010).

17) Hirate $Y$, Hirahara $S$, Inoue $K$, Suzuki A, Alarcon VB, Akimoto K, Hirai T, Hara T, Adachi M, Chida K, Ohno S, Marikawa Y, Nakao K, Shimono A, Sasaki H. Polarity-dependent distribution of angiomotin localizes Hippo signaling in preimplantation embryos. Curr. Biol., 23, 1181-1194 (2013).

18) Cockburn K, Biechele S, Garner J, Rossant J. The Hippo pathway member Nf2 is required for inner cell mass specification. Curr. Biol., 23, 1195-1201 (2013).

19) Dupont S, Morsut L, Aragona M, Enzo E, Giulitti S, Cordenonsi M, Zanconato F, Le Digabel J, Forcato M, Bicciato S, Elvassore N, Piccolo S. Role of YAP/TAZ in mechanotransduction. Nature, 474, 179-183 (2011).

20) Wada K, Itoga $K$, Okano T, Yonemura S, Sasaki H. Hippo pathway regulation by cell morphology and stress fibers. Development, $\mathbf{1 3 8}$, 3907-3914 (2011).

21) Aragona M, Panciera T, Manfrin A, Giulitti S, Michielin F, Elvassore N, Dupont S, Piccolo S. A mechanical checkpoint controls multicellular growth through YAP/TAZ regulation by actin-processing factors. Cell, 154, 1047-1059 (2013).

22) Meng Z, Qiu Y, Lin KC, et al. RAP2 mediates mechanoresponses of the Hippo pathway. Nature, 560, 655-660 (2018).

23) Ooki T, Murata-Kamiya N, Takahashi-Kanemitsu A, Wu W, Hatakeyama M. High-molecular-weight hyaluronan is a hippo pathway ligand directing cell density-dependent growth inhibition via PAR1b. Dev. Cell, 49, 590-604.e9 (2019).

24) Bao Y, Nakagawa $K$, Yang $Z$, Ikeda $M$, Withanage $K$, IshigamiYuasa M, Okuno Y, Hata S, Nishina H, Hata Y. A cell-based assay to screen stimulators of the Hippo pathway reveals the inhibitory effect of dobutamine on the YAP-dependent gene transcription. $J$. Biochem., 150, 199-208 (2011).

25) Miller E, Yang J, DeRan M, Wu C, Su AI, Bonamy GM, Liu J, Peters EC, Wu X. Identification of serum-derived sphingosine1-phosphate as a small molecule regulator of YAP. Chem. Biol., 19, 955-962 (2012).

26) Yu FX, Zhao B, Panupinthu N, Jewell JL, Lian I, Wang LH, Zhao J, Yuan H, Tumaneng K, Li H, Fu XD, Mills GB, Guan KL. Regulation of the Hippo-YAP pathway by G-protein-coupled receptor signaling. Cell, 150, 780-791 (2012). 
27) Mo JS, Yu FX, Gong R, Brown JH, Guan KL. Regulation of the Hippo-YAP pathway by protease-activated receptors (PARs). Genes Dev., 26, 2138-2143 (2012).

28) Varelas X, Miller BW, Sopko R, Song S, Gregorieff A, Fellouse FA, Sakuma R, Pawson T, Hunziker W, McNeill H, Wrana JL, Attisano L. The Hippo pathway regulates Wnt/beta-catenin signaling. Dev. Cell, 18, 579-591 (2010).

29) Azzolin L, Panciera T, Soligo S, Enzo E, Bicciato S, Dupont $S$, Bresolin S, Frasson C, Basso G, Guzzardo V, Fassina A, Cordenonsi M, Piccolo S. YAP/TAZ incorporation in the beta-catenin destruction complex orchestrates the Wnt response. Cell, 158, 157-170 (2014).

30) Barry ER, Morikawa T, Butler BL, Shrestha K, de la Rosa R, Yan KS, Fuchs CS, Magness ST, Smits R, Ogino S, Kuo CJ, Camargo FD. Restriction of intestinal stem cell expansion and the regenerative response by YAP. Nature, 493, 106-110 (2013).

31) Park HW, Kim YC, Yu B, Moroishi T, Mo JS, Plouffe SW, Meng Z, Lin KC, Yu FX, Alexander CM, Wang CY, Guan KL. Alternative Wnt signaling activates YAP/TAZ. Cell, 162, 780-794 (2015).

32) Wu H, Wei L, Fan F, et al. Integration of Hippo signalling and the unfolded protein response to restrain liver overgrowth and tumorigenesis. Nat. Commun., 6, 6239 (2015).

33) Shao D, Zhai P, Del Re DP, Sciarretta S, Yabuta N, Nojima H, Lim DS, Pan D, Sadoshima J. A functional interaction between HippoYAP signalling and FoxO1 mediates the oxidative stress response. Nat. Commun., 5, 3315 (2014).

34) Hong AW, Meng Z, Yuan HX, Plouffe SW, Moon S, Kim W, Jho EH, Guan KL. Osmotic stress-induced phosphorylation by NLK at Ser128 activates YAP. EMBO Rep., 18, 72-86 (2017).

35) Lin KC, Moroishi T, Meng Z, Jeong HS, Plouffe SW, Sekido Y, Han J, Park HW, Guan KL. Regulation of Hippo pathway transcription factor TEAD by p38 MAPK-induced cytoplasmic translocation. Nat. Cell Biol., 19, 996-1002 (2017).

36) DeRan M, Yang J, Shen CH, Peters EC, Fitamant J, Chan P, Hsieh M, Zhu S, Asara JM, Zheng B, Bardeesy N, Liu J, Wu X. Energy stress regulates hippo-YAP signaling involving AMPK-mediated regulation of angiomotin-like 1 protein. Cell Reports, 9, 495-503 (2014).

37) Sorrentino G, Ruggeri N, Specchia V, Cordenonsi M, Mano M, Dupont S, Manfrin A, Ingallina E, Sommaggio R, Piazza S, Rosato A, Piccolo S, Del Sal G. Metabolic control of YAP and TAZ by the mevalonate pathway. Nat. Cell Biol., 16, 357-366 (2014).

38) Enzo E, Santinon G, Pocaterra A, Aragona M, Bresolin S, Forcato M, Grifoni D, Pession A, Zanconato F, Guzzo G, Bicciato S, Dupont S. Aerobic glycolysis tunes YAP/TAZ transcriptional activity. EMBO J., 34, 1349-1370 (2015).

39) Wang W, Xiao ZD, Li X, Aziz KE, Gan B, Johnson RL, Chen J. AMPK modulates Hippo pathway activity to regulate energy homeostasis. Nat. Cell Biol., 17, 490-499 (2015).

40) Mo JS, Meng Z, Kim YC, Park HW, Hansen CG, Kim S, Lim DS, Guan KL. Cellular energy stress induces AMPK-mediated regulation of YAP and the Hippo pathway. Nat. Cell Biol., 17, 500-510 (2015).

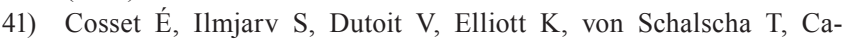
margo MF, Reiss A, Moroishi T, Seguin L, Gomez G, Moo JS, Preynat-Seauve O, Krause KH, Chneiweiss H, Sarkaria JN, Guan KL, Dietrich PY, Weis SM, Mischel PS, Cheresh DA. Glut3 addiction is a druggable vulnerability for a molecularly defined subpopulation of glioblastoma. Cancer Cell, 32, 856-868.e5 (2017).

42) Huh HD, Kim DH, Jeong HS, Park HW. Regulation of TEAD transcription factors in cancer biology. Cells, 8, 600 (2019).

43) Salem O, Hansen CG. The Hippo pathway in prostate cancer. Cells, 8, 370 (2019).

44) Nishio M, Maehama T, Goto H, Nakatani K, Kato W, Omori H, Miyachi Y, Togashi H, Shimono Y, Suzuki A. Hippo vs. Crab: tissue-specific functions of the mammalian Hippo pathway. Genes
Cells, 22, 6-31 (2017)

45) Pan WW, Moroishi T, Koo JH, Guan KL. Cell type-dependent function of LATS1/2 in cancer cell growth. Oncogene, 38, 25952610 (2019).

46) Yabuta N, Okada N, Ito A, Hosomi T, Nishihara S, Sasayama Y, Fujimori A, Okuzaki D, Zhao H, Ikawa M, Okabe M, Nojima H. Lats2 is an essential mitotic regulator required for the coordination of cell division. J. Biol. Chem., 282, 19259-19271 (2007).

47) Ganem NJ, Cornils H, Chiu SY, O’Rourke KP, Arnaud J, Yimlamai D, Thery M, Camargo FD, Pellman D. Cytokinesis failure triggers Hippo tumor suppressor pathway activation. Cell, 158, 833-848 (2014).

48) Fukui H, Terai K, Nakajima H, Chiba A, Fukuhara S, Mochizuki N. S1P-Yapl signaling regulates endoderm formation required for cardiac precursor cell migration in zebrafish. Dev. Cell, 31, 128-136 (2014)

49) Moroishi T, Park HW, Qin B, Chen Q, Meng Z, Plouffe SW, Taniguchi K, Yu FX, Karin M, Pan D, Guan KL. A YAP/TAZ-induced feedback mechanism regulates Hippo pathway homeostasis. Genes Dev., 29, 1271-1284 (2015)

50) Yu FX, Zhao B, Guan KL. Hippo pathway in organ size control, tissue homeostasis, and cancer. Cell, 163, 811-828 (2015).

51) Chen CL, Schroeder MC, Kango-Singh M, Tao C, Halder G. Tumor suppression by cell competition through regulation of the Hippo pathway. Proc. Natl. Acad. Sci. U.S.A., 109, 484-489 (2012).

52) Ohsawa S, Sato Y, Enomoto M, Nakamura M, Betsumiya A, Igaki T. Mitochondrial defect drives non-autonomous tumour progression through Hippo signalling in Drosophila. Nature, 490, 547-551 (2012).

53) Miyamura $\mathrm{N}$, Hata $\mathrm{S}$, Itoh $\mathrm{T}$, Tanaka $\mathrm{M}$, Nishio $\mathrm{M}$, Itoh $\mathrm{M}$, Ogawa Y, Terai S, Sakaida I, Suzuki A, Miyajima A, Nishina H. YAP determines the cell fate of injured mouse hepatocytes in vivo. Nat. Commun., 8, 16017 (2017).

54) Guo P, Lee CH, Lei H, Zheng Y, Pulgar Prieto KD, Pan D. Nerfin-1 represses transcriptional output of Hippo signaling in cell competition. eLife, 8, e38843 (2019).

55) Hashimoto M, Sasaki H. Epiblast formation by TEAD-YAPdependent expression of pluripotency factors and competitive elimination of unspecified cells. Dev. Cell, 50, 139-154.e5 (2019).

56) Geng J, Sun X, Wang P, et al. Kinases Mst1 and Mst2 positively regulate phagocytic induction of reactive oxygen species and bactericidal activity. Nat. Immunol., 16, 1142-1152 (2015).

57) Moroishi T, Hayashi T, Pan WW, Fujita Y, Holt MV, Qin J, Carson DA, Guan KL. The Hippo pathway kinases LATS1/2 suppress cancer immunity. Cell, 167, 1525-1539.e17 (2016).

58) Zhang Q, Meng F, Chen S, Plouffe SW, Wu S, Liu S, Li X, Zhou R, Wang J, Zhao B, Liu J, Qin J, Zou J, Feng XH, Guan KL, Xu P. Hippo signalling governs cytosolic nucleic acid sensing through YAP/TAZ-mediated TBK1 blockade. Nat. Cell Biol., 19, 362-374 (2017).

59) Wang S, Xie F, Chu F, Zhang Z, Yang B, Dai T, Gao L, Wang L, Ling L, Jia J, van Dam H, Jin J, Zhang L, Zhou F. YAP antagonizes innate antiviral immunity and is targeted for lysosomal degradation through IKKvarepsilon-mediated phosphorylation. Nat. Immunol., 18, 733-743 (2017).

60) Liu B, Zheng Y, Yin F, Yu J, Silverman N, Pan D. Toll receptormediated Hippo signaling controls innate immunity in Drosophila. Cell, 164, 406-419 (2016).

61) Yamauchi T, Moroishi T. Hippo pathway in mammalian adaptive immune system. Cells, 8, 398 (2019).

62) Zhang Y, Zhang H, Zhao B. Hippo signaling in the immune system. Trends Biochem. Sci., 43, 77-80 (2018).

63) Hansen CG, Moroishi T, Guan KL. YAP and TAZ: a nexus for Hippo signaling and beyond. Trends Cell Biol., 25, 499-513 (2015). 
64) Nagashima S, Bao Y, Hata Y. The Hippo pathway as drug targets in cancer therapy and regenerative medicine. Curr. Drug Targets, 18, 447-454 (2017).

65) Koo JH, Guan KL. Interplay between YAP/TAZ and metabolism. Cell Metab., 28, 196-206 (2018).

66) Derrien $\mathrm{T}$, Johnson R, Bussotti $\mathrm{G}$, et al. The GENCODE v7 catalog of human long noncoding RNAs: analysis of their gene structure, evolution, and expression. Genome Res., 22, 1775-1789 (2012).

67) $\overline{\text { Batista }}$ PJ, Chang HY. Long noncoding RNAs: cellular address codes in development and disease. Cell, 152, 1298-1307 (2013).

68) Meng Z, Moroishi T, Guan KL. Mechanisms of Hippo pathway regulation. Genes Dev., 30, 1-17 (2016).

69) Ma S, Meng Z, Chen R, Guan KL. The Hippo pathway: biology and pathophysiology. Annu. Rev. Biochem., 88, 577-604 (2019).

70) Morrison DK. The 14-3-3 proteins: integrators of diverse signaling cues that impact cell fate and cancer development. Trends Cell Biol., 19, 16-23 (2009).

71) Kim Y, Jho EH. Regulation of the Hippo signaling pathway by ubiquitin modification. BMB Rep., 51, 143-150 (2018).

72) Lin KC, Park HW, Guan KL. Regulation of the Hippo pathway transcription factor TEAD. Trends Biochem. Sci., 42, 862-872 (2017).

73) Esteller M. Non-coding RNAs in human disease. Nat. Rev. Genet., 12, 861-874 (2011).

74) Anastasiadou E, Jacob LS, Slack FJ. Non-coding RNA networks in cancer. Nat. Rev. Cancer, 18, 5-18 (2018).

75) Ambros V. A hierarchy of regulatory genes controls a larva-toadult developmental switch in C. elegans. Cell, 57, 49-57 (1989).

76) Lee RC, Feinbaum RL, Ambros V. The C. elegans heterochronic gene lin-4 encodes small RNAs with antisense complementarity to lin-14. Cell, 75, 843-854 (1993).

77) Ambros V, Lee RC, Lavanway A, Williams PT, Jewell D. MicroRNAs and other tiny endogenous RNAs in C. elegans. Curr. Biol., 13, 807-818 (2003).

78) Mori M, Triboulet R, Mohseni M, Schlegelmilch K, Shrestha K, Camargo FD, Gregory RI. Hippo signaling regulates microprocessor and links cell-density-dependent miRNA biogenesis to cancer. Cell, 156, 893-906 (2014).

79) Bartel DP. MicroRNAs: target recognition and regulatory functions. Cell, 136, 215-233 (2009).

80) Chaulk SG, Lattanzi VJ, Hiemer SE, Fahlman RP, Varelas X. The Hippo pathway effectors TAZ/YAP regulate DICER expression and microRNA biogenesis through Let-7. J. Biol. Chem., 289, 1886-1891 (2014).

81) Tumaneng K, Schlegelmilch K, Russell RC, Yimlamai D, Basnet H, Mahadevan N, Fitamant J, Bardeesy N, Camargo FD, Guan KL. YAP mediates crosstalk between the Hippo and PI(3)K-TOR pathways by suppressing PTEN via miR-29. Nat. Cell Biol., 14, 1322-1329 (2012)

82) Hikasa H, Sekido Y, Suzuki A. Merlin/NF2-Lin28B-let-7 is a tumor-suppressive pathway that is cell-density dependent and Hippo independent. Cell Reports, 14, 2950-2961 (2016).

83) Li N, Xie C, Lu N. Crosstalk between Hippo signalling and miRNAs in tumour progression. FEBS J., 284, 1045-1055 (2017).

84) Bracken CP, Khew-Goodall Y, Goodall GJ. Network-based approaches to understand the roles of miR-200 and other microRNAs in cancer. Cancer Res., 75, 2594-2599 (2015).

85) Yu SJ, Hu JY, Kuang XY, Luo JM, Hou YF, Di GH, Wu J, Shen ZZ, Song HY, Shao ZM. MicroRNA-200a promotes anoikis resistance and metastasis by targeting YAP1 in human breast cancer. Clin. Cancer Res., 19, 1389-1399 (2013).

86) Wang Y, Xu X, Maglic D, et al. Comprehensive molecular characterization of the Hippo signaling pathway in cancer. Cell Reports, 25, 1304-1317.e5 (2018)

87) Hoefert JE, Bjerke GA, Wang D, Yi R. The microRNA-200 family coordinately regulates cell adhesion and proliferation in hair morphogenesis. J. Cell Biol., 217, 2185-2204 (2018).

88) Gebert LFR, MacRae IJ. Regulation of microRNA function in animals. Nat. Rev. Mol. Cell Biol., 20, 21-37 (2019).

89) Frankish A, Diekhans M, Ferreira AM, et al. GENCODE reference annotation for the human and mouse genomes. Nucleic Acids Res., 47 (D1), D766-D773 (2019).

90) Salmena L, Poliseno L, Tay Y, Kats L, Pandolfi PP. A ceRNA hypothesis: the Rosetta Stone of a hidden RNA language? Cell, 146, 353-358 (2011).

91) Chen LL. The biogenesis and emerging roles of circular RNAs. Nat. Rev. Mol. Cell Biol., 17, 205-211 (2016).

92) Ebert MS, Neilson JR, Sharp PA. MicroRNA sponges: competitive inhibitors of small RNAs in mammalian cells. Nat. Methods, 4, 721-726 (2007).

93) Quinn JJ, Chang HY. Unique features of long non-coding RNA biogenesis and function. Nat. Rev. Genet., 17, 47-62 (2016).

94) Flynn RA, Chang HY. Long noncoding RNAs in cell-fate programming and reprogramming. Cell Stem Cell, 14, 752-761 (2014).

95) Zheng X, Han H, Liu GP, Ma YX, Pan RL, Sang LJ, Li RH, Yang LJ, Marks JR, Wang W, Lin A. LncRNA wires up Hippo and Hedgehog signaling to reprogramme glucose metabolism. EMBO J., 36, 3325-3335 (2017).

96) Wang J, Wang H, Zhang Y, Zhen N, Zhang L, Qiao Y, Weng W, Liu X, Ma L, Xiao W, Yu W, Chu Q, Pan Q, Sun F. Mutual inhibition between YAP and SRSF1 maintains long non-coding RNA, MALAT1-induced tumourigenesis in liver cancer. Cell. Signal., 26, 1048-1059 (2014).

97) Sun Z, Ou C, Liu J, Chen C, Zhou Q, Yang S, Li G, Wang G, Song J, Li Z, Zhang Z, Yuan W, Li X. YAP1-induced MALAT1 promotes epithelial-mesenchymal transition and angiogenesis by sponging miR-126-5p in colorectal cancer. Oncogene, 38, 26272644 (2019).

98) Kim J, Piao HL, Kim BJ, Yao F, Han Z, Wang Y, Xiao Z, Siverly AN, Lawhon SE, Ton BN, Lee H, Zhou Z, Gan B, Nakagawa S, Ellis MJ, Liang H, Hung MC, You MJ, Sun Y, Ma L. Long noncoding RNA MALAT1 suppresses breast cancer metastasis. Nat. Genet., 50, 1705-1715 (2018)

99) Yu W, Qiao Y, Tang X, Ma L, Wang Y, Zhang X, Weng W, Pan $\mathrm{Q}$, Yu Y, Sun F, Wang J. Tumor suppressor long non-coding RNA, MT1DP is negatively regulated by YAP and Runx2 to inhibit FoxA1 in liver cancer cells. Cell. Signal., 26, 2961-2968 (2014).

100) $\overline{\mathrm{Li}} \mathrm{C}$, Wang S, Xing Z, Lin A, Liang K, Song J, Hu Q, Yao J, Chen Z, Park PK, Hawke DH, Zhou J, Zhou Y, Zhang S, Liang H, Hung MC, Gallick GE, Han L, Lin C, Yang L. A ROR1-HER3-lncRNA signalling axis modulates the Hippo-YAP pathway to regulate bone metastasis. Nat. Cell Biol., 19, 106-119 (2017).

101) Wu DM, Wang S, Wen X, Han XR, Wang YJ, Shen M, Fan SH, Zhang ZF, Shan Q, Li MQ, Hu B, Lu J, Chen GQ, Zheng YL. LncRNA SNHG15 acts as a ceRNA to regulate YAP1-Hippo signaling pathway by sponging miR-200a-3p in papillary thyroid carcinoma. Cell Death Dis., 9, 947 (2018).

102) Chen LL, Yang L. Regulation of circRNA biogenesis. RNA Biol. 12, 381-388 (2015).

103) Verduci L, Ferraiuolo M, Sacconi A, Ganci F, Vitale J, Colombo T, Paci P, Strano S, Macino G, Rajewsky N, Blandino G. The oncogenic role of circPVT1 in head and neck squamous cell carcinoma is mediated through the mutant $\mathrm{p} 53 / \mathrm{YAP} / \mathrm{TEAD}$ transcriptioncompetent complex. Genome Biol., 18, 237 (2017).

104) Zhang X, Xu Y, Qian Z, Zheng W, Wu Q, Chen Y, Zhu G, Liu Y, Bian Z, Xu W, Zhang Y, Sun F, Pan Q, Wang J, Du L, Yu Y. circRNA_104075 stimulates YAP-dependent tumorigenesis through the regulation of HNF4a and may serve as a diagnostic marker in hepatocellular carcinoma. Cell Death Dis., 9, 1091 (2018).

105) Zhang J, Liu H, Hou L, Wang G, Zhang R, Huang Y, Chen X, Zhu 
J. Circular RNA LARP4 inhibits cell proliferation and invasion of gastric cancer by sponging miR-424-5p and regulating LATS1 expression. Mol. Cancer, 16, 151 (2017).

106) Zheng X, Chen L, Zhou Y, Wang Q, Zheng Z, Xu B, Wu C, Zhou $\mathrm{Q}, \mathrm{Hu} \mathrm{W}, \mathrm{Wu} \mathrm{C}$, Jiang J. A novel protein encoded by a circular RNA circPPP1R12A promotes tumor pathogenesis and metastasis of colon cancer via Hippo-YAP signaling. Mol. Cancer, 18, 47 (2019).

107) Matsui M, Corey DR. Non-coding RNAs as drug targets. Nat. Rev. Drug Discov., 16, 167-179 (2017).

108) Diez-Cuñado M, Wei K, Bushway PJ, Maurya MR, Perera R, Subramaniam S, Ruiz-Lozano P, Mercola M. miRNAs that induce human cardiomyocyte proliferation converge on the Hippo pathway. Cell Reports, 23, 2168-2174 (2018).

109) Deng J, Lei W, Xiang X, Zhang L, Lei J, Gong Y, Song M, Wang Y, Fang Z, Yu F, Feng M, Sun Z, Chen J, Zhan Z, Xiong J. Cullin 4A (CUL4A), a direct target of miR-9 and miR-137, promotes gastric cancer proliferation and invasion by regulating the Hippo signaling pathway. Oncotarget, 7, 10037-10050 (2016).

110) Wu H, Zhang W, Wu Z, Liu Y, Shi Y, Gong J, Shen W, Liu C. miR-29c-3p regulates DNMT3B and LATS1 methylation to inhibit tumor progression in hepatocellular carcinoma. Cell Death Dis., 10, 48 (2019).

111) Torrini C, Cubero RJ, Dirkx E, Braga L, Ali H, Prosdocimo G, Gutierrez MI, Collesi C, Licastro D, Zentilin L, Mano M, Zacchigna S, Vendruscolo M, Marsili M, Samal A, Giacca M. Common regulatory pathways mediate activity of microRNAs inducing cardiomyocyte proliferation. Cell Reports, 27, 2759-2771.e5 (2019).

112) Tian Y, Liu Y, Wang T, Zhou N, Kong J, Chen L, Snitow M, Morley M, Li D, Petrenko N, Zhou S, Lu M, Gao E, Koch WJ, Stewart KM, Morrisey EE. A microRNA-Hippo pathway that promotes cardiomyocyte proliferation and cardiac regeneration in mice. Sci. Transl. Med., 7, 279ra38 (2015).
113) Guo Y, Cui J, Ji Z, Cheng C, Zhang K, Zhang C, Chu M, Zhao Q, Yu Z, Zhang Y, Fang YX, Gao WQ, Zhu HH. miR-302/367/ LATS2/YAP pathway is essential for prostate tumor-propagating cells and promotes the development of castration resistance. Oncogene, 36, 6336-6347 (2017)

114) Kang W, Huang T, Zhou Y, Zhang J, Lung RWM, Tong JHM, Chan AWH, Zhang B, Wong CC, Wu F, Dong Y, Wang S, Yang W, Pan Y, Chak WP, Cheung AHK, Pang JCS, Yu J, Cheng ASL, To KF. miR-375 is involved in Hippo pathway by targeting YAP1/ TEAD4-CTGF axis in gastric carcinogenesis. Cell Death Dis., 9, 92 (2018).

115) Wang L, Zhang Z, Yu X, Huang X, Liu Z, Chai Y, Yang L, Wang Q, Li M, Zhao J, Hou J, Li F. Unbalanced YAP-SOX9 circuit drives stemness and malignant progression in esophageal squamous cell carcinoma. Oncogene, 38, 2042-2055 (2019).

116) Zhou Y, Huang T, Zhang J, Wong CC, Zhang B, Dong Y, Wu F, Tong JHM, Wu WKK, Cheng ASL, Yu J, Kang W, To KF. TEAD1/4 exerts oncogenic role and is negatively regulated by miR-4269 in gastric tumorigenesis. Oncogene, 36, 6518-6530 (2017).

117) Zhang $Y$, Wang $T$, Wang S, Xiong $Y$, Zhang R, Zhang X, Zhao J, Yang AG, Wang L, Jia L. Nkx2-2as suppression contributes to the pathogenesis of sonic hedgehog medulloblastoma. Cancer Res., 78, 962-973 (2018).

118) Gao L, Cao H, Cheng X. A positive feedback regulation between long noncoding RNA SNHG1 and YAP1 modulates growth and metastasis in laryngeal squamous cell carcinoma. Am. J. Cancer Res., 8, 1712-1724 (2018).

119) Cui X, Piao C, Lv C, Lin X, Zhang Z, Liu X. ZNFX1 anti-sense RNA 1 promotes the tumorigenesis of prostate cancer by regulating c-Myc expression via a regulatory network of competing endogenous RNAs. Cell. Mol. Life Sci., 2019, in press. 